\title{
Social identity shapes debates
}

Energy Res. Soc. Sci. 66, 101492 (2020)

Large-scale system changes are inherently political, as they impact the distribution of resources and power, and benefits and costs are not equally distributed amongst social groups. Because social-political identities provide powerful cues for taking a position on important issues, they may inform attitudes about energy transitions more than substantive issues such as long-term economic security and climate change. Rebecca Colvin from the Australian National University used the case of the Stop Adani Convoy, a multi-week protest against a new coal mine in Queensland, Australia, to examine how social-political identities become activated and shape subsequent energy transition debates.

Analysis of media narratives of the Stop Adani Convoy showed that social identities were emphasized through comparison. The Stop Adani protesters were characterized as environmental activists and elites, in contrast to everyday workers and coal-mining communities at the proposed mine site. Thus, the Stop Adani protesters activated an in-group on the basis of protest participation where the mine was symbolic of climate action, and the opponents developed an in-group on the basis of distinctiveness from the protesters where the mine symbolized community livelihoods and self-determination.

Consequently, these events created a new 'us' versus 'them' that emphasizes antagonism between environmental objectives and the objectives of regional, resourcedependent communities. Reinforcing this false dichotomy through social group membership may stifle constructive debates and slow progress towards just energy transitions.

Jenn Richler

Published online: 20 April 2020

https://doi.org/10.1038/s41560-020-0612-y 